\title{
MENSTRUAL REGULATION: A POTENTIAL BREAKTHROUGH IN FERTILITY CONTROL
}

\author{
G. DAVIS AND D. M. POTTS \\ Population Services International, 103-105 Harley Street, London, W.1, and \\ International Planned Parenthood Federation, 18-20 Lower Regent Street, \\ London SW 1 Y $4 P W$
}

\section{INTRODUCTION}

Menstrual regulation (menstrual aspiration, endometrial aspiration, menses extraction, menses induction) is vacuum curettage of the uterus performed either at, or within a few days of, the expected date of menstruation in women in whom it is possible that unplanned, unwanted conception has occurred.

The technique is not new. Simpson (1872) who attended Queen Victoria in childbirth, described what he called 'dry cupping' of the uterus. Solish (1970) points out that some of the more striking results described by Simpson are probably attributable to having terminated very early pregnancies. In 1927, Bykov described the use of a small syringe and cannula as a method of fertility regulation. In practice, the procedure used was one of menstrual regulation, although the author's own tortuous physiological explanation depended upon a theory of encouraging endometrial hyperaemia to prevent implantation. In the 1950s, Wu \& Wu (1958), in the People's Republic of China, described the use of a hand-syringe to terminate very early pregnancies.

An analogous technique has been used as a diagnostic procedure for some years, especially in Scandinavia. In this latter case, experience of several thousand cases shows the procedure to be simple, safe and virtually without complications, even though it was used mostly on women with pre-existing pelvic pathology. Diagnostic aspiration of this type has been found safe as an outpatient/office procedure (E. Guttorm, personal communication).

The majority of patients, in one series of sixty (Holt, 1970), 'were able to get off the couch immediately after the procedure, dress and resume their normal activities'. The procedure can be performed without cervical dilatation (Holt, 1970; Saunders \& Rowland, 1972) and is acceptable to women without any form of anaesthesia (E. Guttorm, personal communication; Holt, 1970).

The lack of complications and the simplicity of menstrual aspiration and its sister diagnostic technique make this procedure of considerable potential interest as a means of fertility control available both at the point and time of the woman's first contact with professional or para-professional personnel. Where the possibility of unwanted conception is suspected, many women present at the point of first contact within 1 week of the first missed period. If the availability of a procedure to deal with suspected pregnancy was widely known, the number coming at this time would undoubtedly increase further. Use of the technique 
at the time of first contact provides total reassurance that if conception has taken place then it cannot progress. It immediately meets the needs of the woman. Action would be taken before immunological pregnancy tests give reliable results and it would be difficult to prove if fertilization had occurred, thus relieving the woman of certainty that conception had occurred. The knowledge of conception and the interval between seeking help and arriving at a solution of her problem are the harrowing aspects of abortion for many women (Ingham \& Sims, 1972). Menstrual regulation obviates this interval of anxiety and fear.

Contraception is the prevention of pregnancy. Abortion, to use the definition of the unabridged Oxford English Dictionary, is delivery so premature that the fetus cannot live. Menstrual regulation, used as envisaged within 1 week of the missed period, both biologically and surgically appears to fall between the two. Whatever its legal and theological status, it certainly fills an important gap in the existing spectrum of voluntary fertility regulation methods (Pion, Smith \& Hale, 1973). It has the potential of bypassing some of the psychosocial problems in the acceptance of contraception by users, and some of the surgical problems that arise when doctors perform abortion. It seems reasonable to assume that it may be even simpler and safer than the newer methods for outpatient abortion (Berić \& Kupresanin, 1971; Lewis, Lal, Branch \& Beard, 1971; Potts \& Branch, 1971). Menstrual regulation could be an effective solution to the problem of an unplanned and unwanted pregnancy, solving many of the present problems of conception and termination of pregnancy and may have a world application. If it proved effective, the technique would be within the capability of the national services of most underdeveloped countries.

The psychosocial aspects of menstrual regulation have received relatively little attention (David, 1973), but they constitute an area of great importance deserving study.

\section{EMBRYOLOGY}

Assuming ovulation occurs 14 days $( \pm 1)$ before the anticipated day of onset of the next period, then the usual age range of fertilized ova likely to be encountered in the woman seeking menstrual regulation (between 2 and 7 days after the first missed period) would be from a minimum of 14 to a maximum of 22 days. Within this age bracket, the conceptus ranges from $0.75 \times 0.61 \times 0.52$ $\mathrm{mm}$ to $1.3 \times 1.1 \times 1 \mathrm{~mm}$ and the embryonic mass within the blastocyst would be between 0.05 and $0.2 \mathrm{~mm}$ in diameter (Hamilton, Boyd \& Mossman, 1952).

Placental structures, extra-embryonic membranes and decidual tissues are all greatly in excess of the true embryonic components at the times considered. The embryo is in the earliest stages of development. At 13 days the trophoblast has just invaded the maternal tissues as far as the venous system, the embryonic disc has developed and the primitive streak is appearing. No embryonic circulation is developed and the neuro-ectoderm is not differentiated from the remaining embryonic ectoderm. At 22 days after fertilization, the chorionic vesicle is about $1 \mathrm{~cm}$ diameter and the embryonic mass approximately $2 \mathrm{~mm}$ long. Early somite formation will have begun, the neural tube is formed but not closed, the vascular system consists of a loose plexus of primitive blood vessels and the two endothelial tubes which will become the heart are just beginning to fuse, although 
the circulation is not established. From the point of view of the procedure there is nothing that will not traverse a cannula of very small diameter. Naked eye examination cannot distinguish embryonic material and, at the earlier end of the time range considered, embryonic material is unlikely to be found in histological examination.

\section{TECHNIQUE}

In some ways, the technique is closer to that of IUD insertion than that of abortion. No pre-operative preparation is required for the patient, save that she should empty the bladder shortly beforehand. The choice of anaesthetic-and the decision to use one at all-is a matter of individual preference. The options include verbal counselling without anaesthetic, the use of intravenous valium, cervical block alone, or general anaesthesia using ultra-short acting intravenous agents.

Routine aseptic precautions for minor gynaecological procedures should be observed and a no-touch technique used throughout. Bimanual examination is done to determine the location, size and configuration of pelvic organs and the presence or absence of incidental pathology. The procedure can be performed with the patient in the lithotomy position or the left lateral (Holt, 1970; Saunders \& Rowland, 1972). A bivalve speculum is inserted to visualize the cervix. A single or non-toothed volsellum is used to fix the cervix. Cervical dilatation is usually unnecessary. The vacuum cannula is passed through the cervical canal into the uterine cavity and a negative pressure applied. The cannula is rotated for 20 to $30 \mathrm{sec}$ and then removed. Completion of the procedure is signified by the appearance of bubbles in the cannula. At the same time, the contracted uterine cavity grips the cannula producing a characteristic and unmistakable sensation. After withdrawal of the cannula, the vagina is swabbed out, the volsellum and speculum removed and a small amount of bactericidal cream introduced and retained for $12 \mathrm{hr}$ or so by means of a small vaginal pack or tampon. The whole procedure from start to finish, including the time taken to give the anaesthetic, if any is used, takes between 2 and $3 \mathrm{~min}$.

\section{EQUIPMENT}

Cannulae. The Karman cannula (Karman \& Potts, 1972) is very suitable, particularly for multiparous patients. Either the 6 to $7 \mathrm{~mm}$ outside diameter or 4 to $5 \mathrm{~mm}$ may be used. Both are made of a flexible plastic and the tip is designed to bend on application of pressure, making perforation of the uterus extremely unlikely. It is possible that the sealed rounded tip, while facilitating passage through the cervical canal, makes aspiration of the fornices uncertain. The Vabra Aspirator has a hollow stainless steel shaft $3 \mathrm{~mm}$ in diameter and includes a plastic receptacle at the proximal end which retains the aspirated solids (Holt, 1970; Saunders \& Rowland, 1972). Designed as a biopsy instrument, it functions equally well in cases of menstrual regulation.

Possibly the simplest cannula of all can be made by cutting a whistle tip in a short length of Portex polythene tubing (reference no. 800/100/660). The tubing 
is $4.5 \mathrm{~mm}$ outside diameter and traverses the cervical canal with ease. The tip collapses more easily on pressure against the inside of the uterus than the Karman cannula. Portex polythene tubing can be boiled and re-used if wished, although it is very cheap.

Vacuum source. Electrically operated mechanical pumps, as used in vacuum aspiration abortion, are preferable when multiple procedures are planned. Hand- or foot-operated pumps, used to empty a reservoir which can be closed with a stop-cock before the procedure, are cheap but satisfactory alternative sources of vacuum (Lewis, 1971).

For occasional procedures, the Karman syringe (Karman \& Potts, 1972 ) is ideal. The Snyder Surgivac, a sterile plastic, spring-loaded bellows, designed for wound drainage, also provides adequate vacuum. Vacuum can be created in a sealed jar by burning alcohol (Wu \& Wu, 1958; Wu, 1966) or by cooling steam in bottles filled with small stop-cocks (Branch \& Bridgman, 1973). Small sources of vacuum depending upon sealing and without moving parts have the advantage that they cannot be misused to generate a positive pressure in the uterus with the associated risk of air embolus. They have the disadvantage that the vacuum is not continuous, can be less than that supplied by a pump, and if lost, a new source of 'packaged' vacuum must be used. Wu \& Wu (1958) believed the less the vacuum applied, the greater the blood loss.

\section{CLINIGAL EXPERIENGE}

The method has only been used in compliance with the provisions of the 1967 Abortion Act. In a preliminary trial of over 100 cases there were no failures and no recorded complications. The mean blood loss was $10 \mathrm{ml}$, which is less than during menstruation. All the women involved found the procedure convenient and very acceptable. Oral contraceptives were commenced the day following the procedure in all women, although IUD insertion at the time of the procedure is also convenient and acceptable to the women.

While clinical experience with menstrual aspiration as a fertility control technique remains limited, it is useful to supplement the available observations with data from the use of vacuum aspiration as a diagnostic procedure in normally menstruating women. Studies in Britain (Holt, 1970; Saunders \& Rowland, 1972), on women with a wide range of pathological conditions, revealed no infections, no perforations, no cervical damage and negligible blood loss. Biopsy specimens obtained are comparable to those procured by traditional means. In one series of 350 cases from Denmark, there was one post-operative infection.

FOLLOW-UP AND FUTURE ASSESSMENT

It is impossible, in advance of large-scale trials conducted over several years, to assess the method objectively. It is simple to perform and, apparently, the risk of trauma is slight. The immediate morbidity will have to be compared with that of early outpatient abortion, about which considerable data is now available (Tietze \& Lewit, 1972). On the one hand, the procedure, because it involves 
no cervical dilatation, should eliminate the hazard to future pregnancies which some abortion series appear to show (Stallworthy, Moolgoaker \& Walsh, 1971).

On the other hand, any evaluation of short- and long-term morbidity will have to take into account the fact that a proportion of 'redundant' procedures (where menstruation was delayed for some reason other than pregnancy) will be performed when action is taken very early in pregnancy. Perhaps up to $20 \%$ of procedures would fall into this category (Birnberg, personal communication).

\section{MENSTRUAL REGULATION AND CONTRACEPTIVE PRAGTICE}

If the method proves effective, the community of users may well determine the pattern of use and this itself might vary in different situations. In theory, menstrual regulation might be linked to contraceptive practice in one of two ways: (1) many, perhaps the majority, of the women who now proceed to have an abortion, might accept menstrual aspiration if they knew the procedure to be available: it would be used as a 'pre-emptive abortion'. As noted, some 'redundant' operations would also be performed, but the problem of evaluating the technique used in this way is relatively straightforward. Certainly, no technique of contraception is completely effective and 'fail safe' mechanisms are always going to be used, both legally and illegally (Potts, 1970). In countries such as Japan and Hungary contraceptive practice has improved in the presence of freely available abortion (Potts, 1972a). Only experience would be able to demonstrate if the simplicity of menstrual regulation would weaken or leave unchanged the motivation for contraceptive practice. As the procedure would be performed 4 to 8 weeks earlier than most abortions, the total interval between any two conceptions would be slightly shortened (Potts, 1972b). The total number of possible pregnancies in a fertile lifetime would be correspondingly greater even without any change in contraceptive practice; (2) a woman might elect to use no form of contraception but to adopt the procedure of menstrual regulation either (a) when the menses were overdue by a few days or (b) routinely every month immediately before the expected day of menstruation.

Theoretical considerations may militate against either or both and a service to provide the procedure might be designed to discourage either or both. Nevertheless, speculation on these possibilities is wise as any pattern of use is likely to be the result of the type of service provided, modified by as yet unknown consumer pressures.

Potter (1972), reviewing the data on human fecundity from contemporary high-fertility societies such as Taiwan, supplemented with data from historical demography (Henry, 1961), estimates that women in their early twenties require on average seven cycles to conceive, those in their early thirties nine, and women in their forties up to a year. Allowing for delayed periods not associated with pregnancy, the procedure might not be used more than twice a year on average. The distribution of cycles required for conception is skewed and the average is raised by a minority of women who take many cycles to become pregnant. Therefore, if the method were used without any practice of contra- 
ception, there would be a group of women who would need to resort to the procedure several times a year.

\section{CONCLUSION}

Menstrual regulation is a simple technique. Experience, although limited, suggests it is likely to be associated with a high degree of safety. The method is likely to raise less demanding ethical problems than abortion later in pregnancy. In developed countries, it is less open to financial exploitation than abortion as practised. In developing countries, it is more appropriate to many of the available medical resources than abortion later in pregnancy.

It will require a large experience over several years to answer all the obvious questions concerning its use. It will also require experience in several communities in order to determine which of the theoretical relationships with contraceptive practice would prove most popular. It is to be hoped that a start will be made in answering some of these questions as soon as possible.

\section{REFERENCES}

BERIć, B. M. \& KupresANin, M. (1971) Vacuum aspiration using pericervical block, for legal abortion as an outpatient procedure up to 12 th week of pregnancy. Lancet, $\mathbf{i i}, 619$.

BRANGH, B. N. \& BRIDGMAN, H. (1973) Use of pre-evacuated collection bottles for uterine aspiration. Lancet, $\mathbf{i}, 520$.

Byкov, S. G. (1927) Aspiration of the gravid uterus. Vrach. Delo, 10, 1539.

David, H. P. (1973) Psychosocial aspects of menstrual cycles and menses regulation. In The Menstrual Cycle and Missing Menstruation. Ed. P. vander Keep. International Health Foundation, Geneva.

Hamilton, W. J., Boyd, J. D. \& Mossman, H. W. (1952) Human Embryology. Heffer, Cambridge.

Henry, L. (1961) Some data on natural fertility. Eugen. Q.8, 81.

Holt, E. M. (1970) Out-patient diagnostic curettage. F. Obstet. Gynaec. Br. Commonw. 77, 1043.

InGHAM, C. \& Sims, M. (1972) Applicants for abortion at the Royal Northern Hospital, London. $\mathcal{F}$. biosoc. Sci. 4, 351 .

Karman, H. \& Potts, M. (1972) Very early abortion using syringe as vacuum source. Lancet, i, 1051.

LEwIs, S. C. (1971) Vacuum termination of pregnancy. Br. med. $\mathcal{J}$. iv, 365.

Lewis, S. C., Lal, S., Branch, B. \& Beard, R. W. (1971) Out-patient termination of pregnancy. Br. med. F. iv, 606 .

Pron, R. J., Smith, R. G. \& Hale, R. W. (1973) The Hawaii experience. In The Abortion Experience. Eds. H. Osofsky and J. Osofsky. Harper and Row, New York. (in press).

Potrer, R. G. (1972) Additional births averted when abortion is added to contraception. Stud. Fam. Plan. 3, 53.

Potrs, M. (1970) Post contraceptive control of fertility. Int. F. Obstet. Gynec. 8, 957.

Ports, M. (1972a) Abortion and contraception. FPA medical Newsletter, no. 45.

Potrs, M. (1972b) The control of human fertility. In Mammalian Reproduction. Eds. C. R. Austin \& R. V. Short. Cambridge University Press, London.

Potts, M. \& BRANGh, B. (1971) Preliminary assessment of USA abortion experience. Lancet, ii, 619.

SAUNDERS, P. \& Rowland, R. (1972) Vacuum curettage of the uterus without anaesthesia. A comparison with conventional curettage. 7. Obstet. Gynaec. Br. Commonw. 79, 168.

Simpson, J. Y. (1872) Clinical Lectures on the Diseases of Women, p. 635. Appleton Crofts, New York.

Solish, G. I. (1970) Aspiration curettage in the treatment of incomplete abortion. In Advances in Planned Parenthood, No. 5. p. 213. Eds. A. J. Sobrero and C. McKee. Excerpta med. Fdn, Int. Congr. Series no. 207.

Stallworthy, J. A., Moolgoaker, A. S. \& WALSh, J. J. (1971) Legal abortion : a critical assessment of its risks. Lancet, ii, 1245.

TIETZE, C. \& LewIT, S. (1972) Joint programme for the study of abortion (J.P.S.A.): early medical complications of legal abortion. Stud. Fam. Plann. 3, 96.

Wu, P. C. (1966) Use of vacuum bottle in therapeutic abortion: a collective survey. Chin. med. 7. 85, 245.

Wu, Y. T. \& WU, H. C. (1958) Suction in artificial abortion: 300 cases. Chin. F. Obstet. Gynec. 6, 447. 


\section{ADDENDUM}

The ideas covered in this paper have been under considerable scrutiny. Even the phrases to be used to describe the procedure have been evolving. The term 'interception' has been canvassed by one of the authors (G.D.) and found to be widely acceptable.

Since the paper was written, the preliminary trial has been extended and an evaluation of the use of interception by 598 patients published (Brenner, Edelman, Davis \& Kessel, 1973). The results obtained amply vindicate claims made for this technique. A detailed report (Population Report, April, 1973) reviews its present status in some depth.

\section{REFERENCES}

Brenner, W. E., Edelman, D. A., Davis, G. L. R. \& Kesser, E. (1973) Suction curettage for 'menstrual regulation'. In Advances in Planned Parenthood, Vol. 8. Ed. S. Lewit. Excerpta med. Fdn, Amsterdam.

Population Report Series F, No. 2, April, 1973. Department of Medical and Public Affairs, The George Washington University Medical Centre, 2001 S Street, N.W., Washington, D.C. 